of molecular orbital theory. Throughout, complexes are discussed in terms of $\sigma$ or $\pi$ bonding.

The author's personal enthusiasm and experience in this field are clearly apparent, particularly in certain of the descriptions of preparations in which considerable detail is given; an aspect which should add considerably to the value of the book for those actually working in the field. Others will find the wide coverage of this book most helpful in obtaining an appreciation of the present position of organometallics. The book is marred unfortunately by a number of typographical errors. The first edition was cheap at 12s. 6d. The second edition is reasonably priced at 458 . in view of its increased coverage.

D. S. Payne

\section{RADIATION CHEMISTRY OF ORGANIC COMPOUNDS}

Radiation Chemistry of Organic Compounds

By Dr. A. J. Swallow. (International Series of Monographs on Radiation Effects in Materials, Vol. 2). Pp. xiii +380. (London and New York: Pergamon Press, 1960.) 84s. net.

$\mathrm{N}$ this book the author defines his objectives as the presentation of an overall picture of radiation chemistry and a review of the published work on the subject between 1895 and 1958 . He begins with a brief introductory account of the interaction of radiation with matter, and a discussion of the transient species formed by radiation. The transient species are simple in the extreme compared with the highly complex systems to be discussed later in the book.

There follows a chapter on experimental methods which deals, only in outline, with radiation sources, purity of materials-a feature often overlooked, says the author, in some of the experimental work reported on-analysis of products, and dosimetry. In no sense is this a practical manual of techniques, but it surveys very adequately the background to the chapters which follow.

Very wisely, the author devotes the next chapter to the radiation chemistry of aqueous systems, partly because he can illustrate the fundamentals of the mechanism of radiation changes, and because of the importance of aqueous systems for the understanding of radiation effects on biological systems. The four chapters which follow deal with aliphatic and aromatic compounds, polymers and dyestuffs. In these chapters the author's task was difficult in the extreme for, as he says, mechanisms are not yet fully understood even for simple molecules. Thus, much of the material presented catalogues the results of radiation of a vast range of compounds, with comments on mechanism where this is even partially understood. I would have liked more comment on mechanism, no matter how speculative it had to be. The author deserves great credit for the thoroughness of his searches before presenting this-and the other material in the book.

The next chapter deals extensively with radiation effects on substances of biological interest, with limited reference to in vivo systems, and the final chapter deals with such diverse topics as the origin of organic compounds in the history of the Earth, radiotherapeutics, sterilization of pharmaceutical products, food, and detailed investigation of the economics of commercial radiation. This chapter contains the surprisingly few examples of commercially feasible radiation processes which have been discovered, in spite of the vast amount of irradiation experimentation in the laboratory. The importance of radiation damage to organic coolants and lubricants for reactors is also discussed.

Although it has a few stylistic defects, the book is written with great clarity, without unnecessary preamble or loquaciousness, in a refreshingly direct way. It covers an amazing range of material, which is referred to by a sensible reference system collected at the end of the book. The chapters are constructed according to well-established rules of learninga brief statement of the aims of the chapter, the detailed discussion, then a brief statement of the results.

The main value of the book lies in the fact that it makes readily accessible the state of knowledge about particular systems. Its discussion of mechanism is necessarily brief; but since such a book as this in a subject which is rapidly growing will surely be revised, the author might consider greater elaboration of the discussion on fundamental aspects of the subject, whether the knowledge is speculative or tentative or otherwise, perhaps at the price of compressing some of the factual matter into tabular form. The present structure of the book reflects the way in which the subject has grown empirically, without a detailed and exact theoretical basis. Perhaps this situation will change in the cycle of experiment, theoretical interpretation, prediction, and further enlightened experimentation.

S. J. THOMSON

\section{PHYSICAL METHODS OF ORGANIC CHEMISTRY}

\section{Physical Methods of Organic Chemistry}

Part 3. Edited by Arnold Weissberger. Third, completely revised and augmented edition. (Technique of Organic Chemistry, Vol. 1, Part 3.) Pp. xii $+1799-2634+13$. 184s. Part 4. Edited by Arnold Weissberger. Third, completely revised and augmented edition. (Technique of Organic Chemistry, Vol. 1, Part 4). Pp. xii $+2635-3539+65$. 195s. (New York: Interscience Publishers, Inc.; London: Interscience Publishers, Ltd., 1960.)

HE general features of Physical Methods of Organic Chemistry have been indicated by the present reviewer when commenting on Parts 1 and 2, which were issued a year ago (Nature, 189, 954, 1961). Parts 3 and 4, which have now appeared, keep to the same general type in that they are mainly written by physicists for chemists and do not explain sufficiently the scientific significance of the types of measurements which they describe. However, organic chemists to whom the volumes have, by title, been commended will find Parts 3 and 4 of much more interest than Parts 1 and 2, since these survey the major optical and electrical techniques in use to-day for the investigation of molecular structure.

Part 3 deals mainly with optical measurements. Two sections on "Spectroscopy and Spectrophotometry" from the old edition have now been expanded to five chapters without inclusion of superfluous material. The chapter on "Ultraviolet and Visible Spectroscopy" (150 pages) can be commended as a well-balanced review in which technical improvements are brought to notice and the structural significance of experimental results is explained in simple terms. 